\title{
Measurement of the intensity of construction and installation works taking into account the level of organizational and technological reliability
}

\author{
Vadim Kabanov ${ }^{1, *}$ \\ ${ }^{1}$ Moscow State University of Civil Engineering, Yaroslavskoe shosse, 26, Moscow, 129337, Russia
}

\begin{abstract}
In the work of the object of study, organizational and technological reliability (OTR) is presented as the ability of the construction process to maintain a specified (design) value of the intensity of construction and installation works (CIW). The subject of the study is the scope of OTR. The use of the indicator "probability of achievement of the set values of intensity of CIW" for planning of growth of productivity of work is capable to significantly increase reliability of the planned development, including taking into account the last achievements of science and technology. The aim of this work is to consider options for modifying the intensity of CIW based on the specific OTR. To achieve the goal, we tackled the problem of assessing the influence of methods of curve plotting cumulative probabilities for the rate of change of intensity of construction, and also showed alternative plans for the growth of labor productivity taking into account OTR. As a result of the study, the author comes to the conclusion about the identity of the probability of achieving a given level of intensity of production of CIW and the duration of construction of buildings and structures. Examples of alternative planning of productivity growth taking into account OTR are considered. The influence of the construction method of the curve of accumulated probability on the growth rate of intensity of production of CIW is proved.
\end{abstract}

\section{Introduction}

The practice of modern construction industry shows that contractors often violate the deadlines established by contracts. The existing procedure for calculating construction duration does not take into account the probabilistic nature of the indicators used in the development of calendar plans. For example, the duration of construction is the result of dividing the volume by the intensity of work. Construction volume refers to a constant value and cannot be measured by probability. The quantitative value of the intensity of construction and installation works relates to stochastic values. Consequently, the indicator of probability of intensity of works can be used to assess the reliability of the duration of construction. Provided that each value of intensity of production of construction works belongs concrete (from all possible) the organizational and technological decision of construction, it is obvious

\footnotetext{
${ }^{*}$ Corresponding author: kabanovvn@yandex.ru
} 
that probability of intensity value can be considered as the indicator of reliability of the organizational and technological decision in construction.

Published research results offer a range of approaches to measuring the reliability of the functioning of organizational and technological solutions of construction. However, no ideas anywhere of the ability to control the value of the intensity of work while ensuring a given (project) level of organizational and technological reliability.

For example, the intensity of work (duration or speed of construction) is considered as a function of approximation of changes in the actual values of labor costs [1]. Organizational and technological models of construction production [2], in particular mathematical models of intensity of performance of works [3] (for example: $J=V / t$, where $J$ - the intensity of work; $V$ - the amount of work, $t$ - the duration of construction) became widespread. Often, publications emphasize the importance of organizational and technological design in order to comply with the normative (specified) terms of work $[4,5]$, determine the dependence of the duration of construction on the amount of work performed per shift [6], identify the impact of the volume of stocks of materials and structures on-site warehouse on the intensity of construction [7].

Some authors consider the intensity of construction works (CIW) not in physical units, but in monetary units [8]. At the same time, it is possible to expand the scope of the practical application of the indicator "intensity of CIW", for example, in the case of an assessment of the economic efficiency of the proposed construction equipment by the Modigliani -Miller method $[9,10]$, which is based on the calculation of $N P V$ and IRR. Besides, the models tested in modern financial markets can be adapted to assess the effectiveness of investment projects with different values of construction duration [11].

Assessment of the value of organizational and technological reliability in relation to the indicator "intensity of production of CIW" is carried out at the stage of development of organizational and technological construction project [12]. In the process of designing the author proposes to evaluate the reliability of the estimated duration. The duration should be considered as a function of the intensity of work during the entire time of creation of finished construction products $[13,14]$. To estimate the level of OTR, the probability of production intensity for each work lying on the critical path $[15,16,17]$ is proposed to be considered at each time interval. It is important to emphasize the significant impact of structural changes that can affect the value of OTR and the cost of construction as a whole [18].

In the present work does not discuss how to calculate the value of organizationaltechnological reliability. Reliability refers to the deviation from the reference or project (specified) value (for example, $p=0.8$ ). In the published results of previous studies, this approach is found in assessing the reliability of structures [19] (theoretical and probabilistic model for comparing the mean value and standard deviation of the hazardous parameter of the structure), and in addition to the evaluation of OTR [20, 21]. In questions of studying OTR there are cases of estimation of borders of change of intensity of production of CIW [22], for example, "at decomposition of the main elements of the construction project [23]". The author of this work shares the need to assess the internal (hidden) capabilities of organizational and technological solutions of construction [24, 25].

Hypothesis. The practical application of probability theory methods to assess the level of organizational and technological reliability in construction involves the determination of such a value of the intensity of CIW production, which corresponds to a given level of reliability (probability, reliability).This technique allows to form scientifically based longterm plans, which are aimed at increasing the intensity of CIW production, taking into account the specified level of organizational and technological reliability.

Purpose: to consider options for measuring the intensity of CIW taking into account the specified organizational and technological reliability.

Research problem: 
- to consider the influence of the variants of the curve of accumulated probabilities on the value of the intensity of work, which correspond to the specified level of organizational and technological reliability (for example, $p=0,8$ );

- show options of planning of growth of productivity (intensity of production of works) taking into account the set (project) level of organizational and technological reliability.

The object of the study is organizational and technological reliability (OTR) as the ability of the construction process to maintain a given (project) indicator of the intensity of construction works (CIW). Subject of research - the field of application OTR.

\section{Methods}

Traditional methods of probability theory have weight and force in the case of constructing a curve of accumulated probabilities. The discussion in the society of mathematicians about the rules of constructing the curve of accumulated probabilities [26] prompted the author to compare the curves with different number of intervals. The estimated probability density function is unknown, therefore the number of intervals affects the appearance of the frequency distribution of the final sample $[3,26]$.

The construction of class intervals belonging to a random variable was performed by standard methods. Computational procedures, the results of which are summarized in tables, did not go beyond the limits provided by the classical theory of probability. The practical use of the results of calculations for the construction of plans for increasing the intensity of SMR is based on the rules of elementary algebra and analytic geometry.

\section{Results and Discussion}

In this paper, we consider the management of the intensity of production of works with a given level of OTR.

The author gives the solution of the problem in relation to the technological processes of construction with a high proportion of manual labor (for example, brickwork, installation of partitions from URL, painting and other types of finishing works). The results of the research are presented for the following conditions of work:

- the number of workers in crew (link) does not change throughout all time necessary for performance of works under the contract $\left(\mathrm{N}_{\mathrm{R}}=\right.$ const);

- there are at least 100 quantitative values (observations) that describe the change in the intensity of production of CIW link (brigade) in the performance of this construction process $(\mathrm{N}=100)$;

- for sampling of quantitative values $(\mathrm{N}=100)$ of intensity of works by a link (WR) the condition is fulfilled: $\frac{W_{R \max }-W_{R \min }}{W_{R \max }} \geq 0,3$;

- the number of intervals $(\mathrm{k})$ at which the range of change in intensity values (WRmin $<$ WR $<$ WRmax) is divided does not change during the time of control of the value of the indicator;

- the set value of organizational and technological reliability for the construction process is directive established $\mathrm{p}=0,8$;

Initial condition. Let the team (link) consists of NR workers and NR $=$ const throughout the construction works. The quantitative composition of teams does not change from the point of view of reception of additional employees, however, on the construction site, the actual number of workers may vary, for example, in the absence of one or more workers for a good (or valid reason). The change in the number of workers in the team is recorded by changing 
the value of the intensity of work by the team in a predetermined unit of time (for example, an hour or a change).

The intensity of work is understood as the amount of work that is performed by a team of workers per unit time. The amount of work is measured in physical units. As a unit of time, it is most often agreed to use one hour or one shift. The intensity of works by the team is the sum of the productivity of each worker who participates in the process of work. The productivity of one worker is inversely proportional to the value of labor costs that are required to perform a single amount of work. The amount of labor costs that are required to perform a single amount of work is established by the existing regulatory documents (for example, in Russia - SEES).

Decision. In the presence of 100 values $(\mathrm{N}=100)$ which describe intensity of works by team of workers, it is necessary to establish such value of intensity for which the level of organizational and technological reliability will be not less than $0,8(p=0,8)$. Classical methods of probability theory suggest the construction of the accumulated probability curve (cumulative curve) on the basis of dividing the range of the initial sample by a number of intervals $(\mathrm{k})$. There are regulatory guidelines for determining the number of intervals. However, the existing guidance clearly does not answer the question about the number of intervals depending on sample size $[5,26]$, therefore we present calculation results for several variants (Table. 1).

The use of the curve of accumulated probability ensures determination of the probability that the next value of the sample will be not less than the specified (corresponding to the agreed value of probability). This logic meets the requirements for use as an indicator of OTR, and the methods of its calculation. To find such a value, a accumulated probability curve is constructed based on the existing array of values $(\mathrm{N}=100)$, which describes the change in the intensity of work. The required value must satisfy the specified value of organizational and technological reliability (probability, $\mathrm{p}=0.8$ ). For ease of presentation of the results, it is advisable to arrange the sample values in ascending order from the minimum to the maximum value. Then the sequence number of the value that is taken to calculate the duration of the work will depend on the number of intervals by which the range of sample values (WRmin $<\mathrm{WRn}<\mathrm{WRmax}$ ) is divided. Note that the difference between the minimum

$$
\frac{W_{R \max }-W_{R \min }}{W_{R \max }}=0,996
$$

and maximum values is very significant for the sample under consideration, which provides an illustration of the advantages of this method.

Table 1. Characteristics of the array of values describing the change in the intensity of work.

\begin{tabular}{|c|c|c|c|c|c|}
\hline \multirow[b]{2}{*}{$\begin{array}{l}\text { The number } \\
\text { of intervals, } \mathrm{k}\end{array}$} & \multicolumn{2}{|c|}{ The calculated interval } & \multicolumn{2}{|c|}{ Calculated value } & \multirow[b]{2}{*}{$\begin{array}{c}\text { Increment } \\
\Delta \mathrm{W}_{\mathrm{R}}\end{array}$} \\
\hline & $\mathrm{W}_{\mathrm{R}, \min }$ & $\mathrm{W}_{\mathrm{R}, \max }$ & $\begin{array}{c}\text { A room in an } \\
\text { ordered } \\
\text { sample, } \mathrm{n}\end{array}$ & $\begin{array}{c}\text { Value } \\
\text { relative to } \\
\text { the index } \\
W_{\text {Rmin }}\end{array}$ & \\
\hline 1 & 2 & 3 & 4 & 5 & 6 \\
\hline 7 & $1,78 \mathrm{~W}_{\mathrm{Rmin}}$ & $2,16 \mathrm{~W}_{\mathrm{Rmin}}$ & 34 & $1,74 \mathrm{~W}_{\mathrm{Rmin}}$ & $0,382 \mathrm{~W}_{\mathrm{Rmin}}$ \\
\hline 8 & $1,70 \mathrm{~W}_{\mathrm{Rmin}}$ & $2,04 \mathrm{~W}_{\mathrm{Rmin}}$ & 28 & $1,76 \mathrm{~W}_{\mathrm{Rmin}}$ & $0,344 \mathrm{~W}_{\mathrm{Rmin}}$ \\
\hline 9 & $1,62 \mathrm{~W}_{\mathrm{Rmin}}$ & $1,93 \mathrm{~W}_{\mathrm{Rmin}}$ & 26 & $1,67 \mathrm{~W}_{\mathrm{Rmin}}$ & $0,306 \mathrm{~W}_{\mathrm{Rmin}}$ \\
\hline 10 & $1,56 \mathrm{~W}_{\mathrm{Rmin}}$ & $1,84 \mathrm{~W}_{\mathrm{Rmin}}$ & 26 & $1,66 \mathrm{~W}_{\mathrm{Rmin}}$ & $0,275 \mathrm{~W}_{\mathrm{Rmin}}$ \\
\hline
\end{tabular}

The values of the coefficients at the minimum sample value $\left(W_{R \min }\right)$ depend on the distribution of the values of the intensity of work in the initial array of observations. Among the characteristics of the array should be attributed to the number of the value of the intensity of production which corresponds to a given value of organizational and technological 
reliability $(\mathrm{p}=0.8)$. The increment value does not depend on the nature of the distribution of values in the source array, but is determined by dividing the range by the value shown in column 1 , table. 1. It is clear that for each organizational and technological decision of erection of the separately taken building and a construction which is carried out by forces of the concrete construction organization, the characteristic of distribution of intensity of production of works will be individual. An even greater individuality of the accumulated probability curve, which is built for a particular array of values, emphasizes the number of intervals $(k)$, into which the set of changes in quantitative values is divided (Fig. 1).

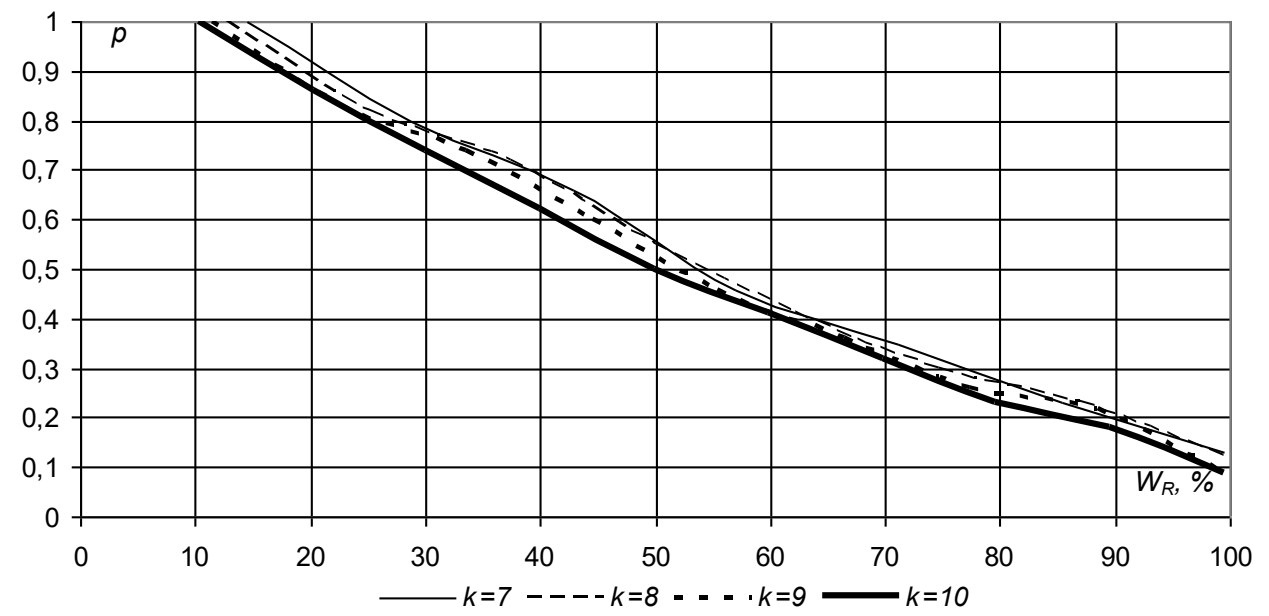

Fig. 1. Accumulated probability curves depending on the number of intervals $(k)$.

Elementary analysis of the initial array of quantitative values suggests that this distribution of values has a significant relative difference between the minimum and maximum values $\left(\frac{W_{R \max }-W_{R \min }}{W_{R \max }}=0,996\right.$

values of the sample characterizes the internal potential, which has the proposed organizational and technological solution. The greater the value of the relative difference, the higher the internal potential. Internal capacity is understood as the possibility of increasing the intensity of production without external influence on the production of CIW (for example, additional costs). External influence refers to the replacement of a hand tool, improvement of work technology and other changes.

The methods of probability theory involve changing the number of values in the sample without adjusting the number of intervals $(\mathrm{k})$. It is important to emphasize that the addition of the original array of values with the actual data that describes the intensity of work, leads to a change in the reliability value (probability). Consequently, at a given level of reliability (probability, $\mathrm{p}=0.8$ ), the value of the intensity of CIW production will change. For example, a brigade is set to a volume per time unit that is equal to or greater than a fixed value. Suppose a team manages to complete such a task for a long period of time. Then it is possible to determine such a value of the number of time intervals, after which it is advisable to increase the replacement task (the amount of work per unit time) by the increment ( $\Delta$ WR). It is logical that the increase in the volume of work per unit time is accompanied by an increase in wages in the amount of which is proportional to the increase in the intensity of work. To calculate the number of time intervals after which it is advisable to increase the intensity of work by the increment value $\left(\Delta W_{R}\right.$ ), you can calculate using an expression: 


$$
\Delta N=\frac{p N-(N-m)}{1-p}=\frac{m-0,2 N}{0,2}
$$

where $\Delta \mathrm{N}$ is the number of observations that satisfies the $\mathrm{W}_{\mathrm{R}(\mathrm{p}=0,8)}<\mathrm{W}_{\mathrm{N}+\mathrm{i}}(\mathrm{i}=1,2,3 \ldots$. $\Delta \mathrm{N}$ ), the addition of which to the initial array of values will provide an increase in the intensity of work on $\Delta \mathrm{W}_{\mathrm{R}}$, if $\mathrm{W}_{\mathrm{R}(\mathrm{p}=0.8)}$ - the calculated (project) intensity value that corresponds to the specified level of reliability $(\mathrm{p}=0,8)$, then when adding $\mathrm{n}$ observations, the new value of the intensity of work $\left(\mathrm{W}_{\mathrm{R} 1(\mathrm{p}=0.8)}\right)$, which corresponds to the specified level of reliability $(\mathrm{p}=0,8)$, is $\mathrm{W}_{\mathrm{R} 1(\mathrm{p}=0.8)}=\mathrm{W}_{\mathrm{R}(\mathrm{p}=0.8)}+\Delta \mathrm{W}_{\mathrm{R}}$;

- $p$-the set level of organizational and technological reliability (probability, $p=0,8$ );

- $\mathrm{N}$ - the number of values in the initial array of values, which is used to find the calculated (design) value of the intensity of work, which corresponds to the specified level of reliability (probability, $\mathrm{p}=0.8$ );

$-m$ - the number of values in the initial sample that exceed the calculated (design) value of the intensity of work.

The practical application of the expression 1 allows a high degree of accuracy to plan the growth of labor productivity, which is achieved through the fuller use of internal reserves of any organizational and technological solutions. With respect to the distribution of the original values (Fig. 1) plan to increase productivity, for example, by $20 \%$, depending on the number of intervals, consists of the number of time intervals that are shown in the table. 2.

Table 2. The plan of growth of labor productivity (intensity of works) taking into account observance of requirements for ensuring organizational and technological reliability.

\begin{tabular}{|c|c|c|c|c|c|}
\hline \multirow{2}{*}{$\begin{array}{l}\text { The number } \\
\text { of intervals, } \mathrm{k}\end{array}$} & \multirow{2}{*}{$\begin{array}{c}\text { Design } \\
\text { (initially } \\
\text { calculated) } \\
\text { intensity, } \\
\mathrm{W}_{\mathrm{R}(\mathrm{p}=0,8)}\end{array}$} & \multicolumn{2}{|c|}{$\begin{array}{l}\text { The boundaries of the } \\
\text { intervals }\end{array}$} & \multirow{2}{*}{$\begin{array}{l}\text { number of } \\
\text { observations } \\
\text { for which the } \\
\text { intensity is } \\
\text { higher than the } \\
\text { design, } \Delta \mathrm{N}\end{array}$} & \multirow{2}{*}{$\begin{array}{l}\text { Changes in } \\
\text { intensity, } \\
\mathrm{W}_{\mathrm{R} 1(\mathrm{p}=0,8)}\end{array}$} \\
\hline & & $\min$ & $\max$ & & \\
\hline 1 & 2 & 3 & 4 & 5 & 6 \\
\hline \multirow{2}{*}{7} & $1,77 \mathrm{~W}_{\mathrm{Rmin}}$ & $1,39 \mathrm{~W}_{\mathrm{Rmin}}$ & $1,77 \mathrm{~W}_{\mathrm{Rmin}}$ & 70 & $2,16 \mathrm{~W}_{\mathrm{Rmin}}$ \\
\hline & $2,16 W_{R \min }$ & $1,77 \mathrm{~W}_{\mathrm{Rmin}}$ & $2,54 \mathrm{~W}_{\mathrm{Rmin}}$ & 100 & $2,92 \mathrm{~W}_{\mathrm{Rmin}}$ \\
\hline \multirow{2}{*}{8} & $2,04 \mathrm{~W}_{\mathrm{Rmin}}$ & $1,62 \mathrm{~W}_{\mathrm{Rmin}}$ & $2,04 \mathrm{~W}_{\mathrm{Rmin}}$ & 40 & $2,39 \mathrm{~W}_{\mathrm{Rmin}}$ \\
\hline & $2,39 \mathrm{~W}_{\mathrm{Rmin}}$ & $2,04 \mathrm{~W}_{\mathrm{Rmin}}$ & $2,39 \mathrm{~W}_{\mathrm{Rmin}}$ & 85 & $2,73 \mathrm{~W}_{\mathrm{Rmin}}$ \\
\hline \multirow{2}{*}{9} & $1,93 \mathrm{~W}_{\mathrm{Rmin}}$ & $1,62 \mathrm{~W}_{\mathrm{Rmin}}$ & $1,93 \mathrm{~W}_{\mathrm{Rmin}}$ & 30 & $2,23 \mathrm{~W}_{\mathrm{Rmin}}$ \\
\hline & $2,23 \mathrm{~W}_{\mathrm{Rmin}}$ & $1,93 \mathrm{~W}_{\mathrm{Rmin}}$ & $2,23 \mathrm{~W}_{\mathrm{Rmin}}$ & 70 & $2,54 \mathrm{~W}_{\mathrm{Rmin}}$ \\
\hline \multirow{2}{*}{10} & $1,84 \mathrm{~W}_{\mathrm{Rmin}}$ & $1,56 \mathrm{~W}_{\mathrm{Rmin}}$ & $1,84 \mathrm{~W}_{\mathrm{Rmin}}$ & 30 & $2,11 \mathrm{~W}_{\mathrm{Rmin}}$ \\
\hline & $2,11 \mathrm{~W}_{\mathrm{Rmin}}$ & $1,84 \mathrm{~W}_{\mathrm{Rmin}}$ & $2,11 \mathrm{~W}_{\mathrm{Rmin}}$ & 60 & $2,39 \mathrm{~W}_{\mathrm{Rmin}}$ \\
\hline
\end{tabular}

If we proceed from the condition that each observation is equivalent to a single period of time, then the values in column 5 of the table. 2 shows the time required to achieve the specified performance value, provided that the specified reliability level is met. The duration of achievement of the established productivity growth, depending on the choice of number of intervals $(k)$, is shown in Fig. 2. 


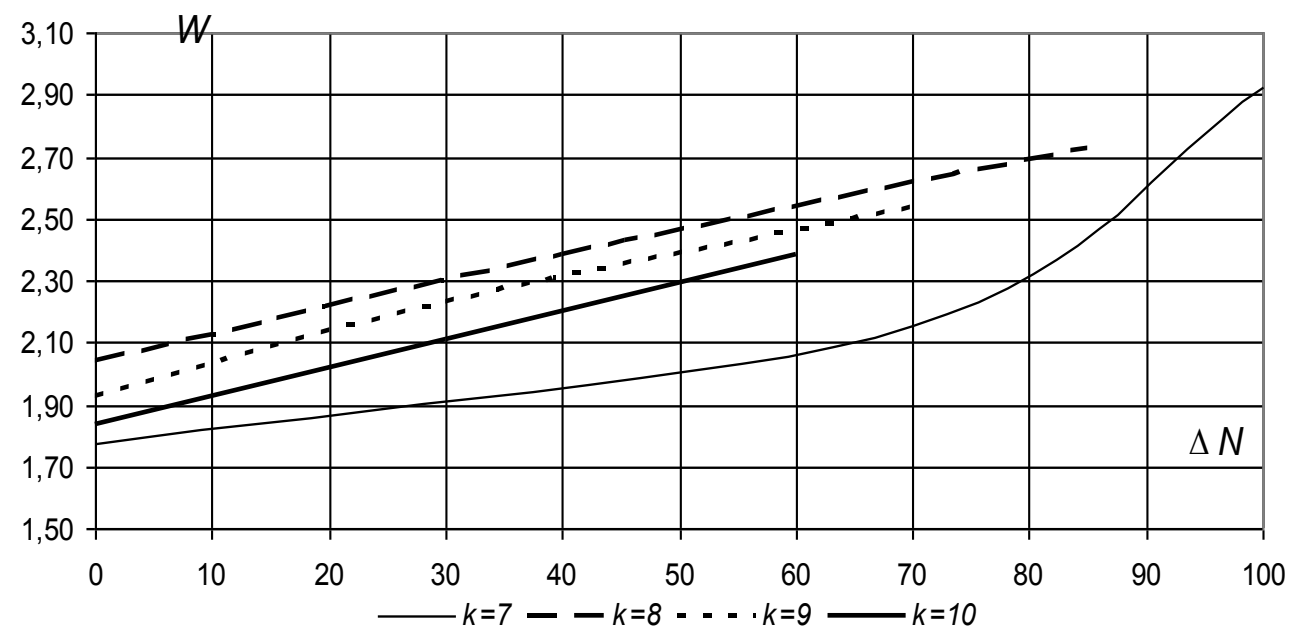

Fig. 2. The time required to increase the intensity of work with a specified level of reliability, depending on the number of intervals set for the value sampling study.

The author's proposals on managing the intensity of construction in contrast to the traditional application of the indicator "labor costs" [1 - 5], based on the use of the most common [6] indicator "intensity of production of CIW." This approach has a universal character, and is applicable to describe fully mechanized processes and works that are performed manually. Measurement of the indicator "intensity of CIW production" in physical units provides higher reliability in comparison with application of monetary characteristics $[8-10,27]$. Simple methods of calculation do not require special mathematical training that is needed, for example, to apply the theory of fuzzy sets [12].

The considered example for one construction process does not exclude the possibility of its application in the construction of models of buildings and structures [13 - 17].

From the point of view of the author, organizational and technological reliability needs to describe the probability of the intensity of construction, assessment of the reliability of the probability value [18-22] is applicable for fully mechanized (automated or robot-controlled) processes.

\section{Conclusions}

1. The use of classical methods of probability theory allows us to find intervals of variation in the intensity of work in accordance with a given level of reliability.

It should be emphasized that the probability value of the duration of works (calculated by the intensity value on the curve of accumulated probabilities of construction intensity) will be identical to the reliability level (probability or reliability) of the intensity value of works.

2. The accumulated probability curve can be used for long-term planning of labor productivity growth.

At the same time, the process of increasing productivity can be limited to a specified level of organizational and technological reliability.

3. The practical application of probability theory methods for calculating the design values of the intensity of work with a given level of organizational and technological reliability (probability) shows the significant impact of the number of intervals on which the range is divided (from the minimum to the maximum value of the sample) on the calculated values (W, column 5, table. 1), and also on duration of achievement of the set growth (W, column 5, table. 2, Fig. 2). 


\section{References}

1. S.A. Sychev, Industrial and civil engineering 11, 67-70 (2015)

2. E.A. Korol', S.V. Komissarov, P.B. Kagan, Industrial and civil engineering 3, 43-45 (2011)

3. V.V. Bredihin, N.V. Bredihina, Proceedings of the Southwest State University 5, 46-51 (2015)

4. A. Volkov, V. Chulkov, R. Kazaryan, Procedia Engineering 91, 368-372 (2014) DOI: 10.1016/j.proeng.2014.12.077

5. L.V. Kievskij, S.A. Tihomirov, E.I. Kuleshova, V.A. Sheglov, Industrial and civil engineering 11, 41-49 (2016)

6. V.A. Grigor'ev, P.P. Olejnik, Mechanization of construction 10, 39-41 (2015)

7. D.G. Odincov, O.V. Demidenko, News of higher educational institutions. Construction 5, 67-71 (2003)

8. K.Yu. Kulakov, S.D. Stepanova, Real estate: economics, management 2, 32-35 (2012)

9. F. Modigliani, M.H. Miller, Taxes and the Cost of Capital (A Correction Ibid, 1963)

10. F. Modigliani, M.H. Miller, The Cost of Capital, Corporation Finance and the Theory of Investment (Amer. Econ. Rev. 1958)

11. V.N. Kabanov, E.V. Mihajlovam, Economics of Construction 4, 67-79 (2012)

12. A.A. Lapidus, A.N. Makarov, 5th International Scientific Conference IPICSE, 05003 (2016) DOI: $10.1051 /$ matecconf $/ 20168605003$

13. Y.B. Kalugin, News of higher educational institutions. Construction 7, 26-37 (2015)

14. V.Z. Velichkin, Magazine of Civil Engineering 7, 26-37 (2015)

15. E.M. Goldratt, Critical Chain, Great Barrington (North River Press, MA, 1997)

16. E.M. Goldratt, Theory of Constrains, Croton-on-Hudson (North River Press, NY, 1990)

17. S.A. Bolotin, M.A. Kotovskaya, Real estate: economics, management 3-4, 38-43 (2014)

18. A.V. Ginzburg, P.B. Zhavnerov, Vestnik MGSU 3, 196-200 (2013)

19. V.V. Stolyarov, N.V. Shchegoleva, Russian journal of transport engineering 3, 4 (2006) http://t-s.today/PDF/02TS316.pdf

20. G.I. Abdullaev, V.Z. Velichkin, T.N. Soldatenko, Magazine of Civil Engineering 3, 4350 (2013)

21. V.R. Molodeckij, T.A. Cenackvich, Bulletin of Prydniprovs'ka State Academy of Civil Engineering and Architecture 9, 47-54 (2015)

22. A.A. Lapidus, Applied Mechanics and Materials 584-586, 2230-2232 (2014) DOI: 10.4028/www.scientific.net/AMM.584-586.2230

23. A.A. Lapidus, Vestnik MGSU 12, 114-123 (2016)

24. P. Oleinik, T. Kuzmina, Z. Victor, MATEC Web of Conferences 05019 DOI: $10.1051 /$ matecconf $/ 20168605019$

25. A.V. Ginzburg, Proceedings of The International Conference (The University of Nottingham, Nottingham, 2010)

26. Y.N. Orlov, Preprints Keldysh Institute of Applied Mathematics 14, 26 (2013) http://library.keldysh.ru/preprint.asp?id=2013-14

27. E.V. Mihajlova, Business. Education. Law 3, 66-70 (2011) 